\section{Future plans for Thorax}

Assuming the role of executive editor of Thorax is a great challenge and privilege. The extremely hard working Anne Tattersfield has passed the journal over in a healthy state, stamped by her own progressive ideas. The review articles commissioned over the last three years, for example, have been an excellent innovation and will continue. Anne has put a huge effort into Thorax and deserves our profound thanks.

The initial task of the associate editors and myself will be to continue to attract first class articles. Thorax receives many more papers for consideration than any other European respiratory publication and we will now endeavour to deal with these even more efficiently than before. Our aim must be to shorten considerably our reviewing time, and also the interval between a resubmission and the final verdict. We will be streamlining the reviewing system by monitoring all manuscripts from the new editorial office at the Royal Brompton Hospital. This office will identify and chase up slow reviewers, aiming to get a decision from the associate editor and executive editor back to the authors within six weeks of original receipt. Similar pressure will be exerted on a paper once it has been resubmitted if a revision was requested before a final decision.

The number of reviewers devoting time and expertise to Thorax is around 300 each year and in future years we will acknowledge our indebtedness by printing their names in the December issue. We will be taking particular care not to overburden individual reviewers and therefore an even larger number of people may be called on to help us with manuscripts. We hope that you will respond promptly and help to provide the rapid assessment we desire.

I hope to broaden the content of Thorax to include research into subjects closely but not so directly concerned with clinical thoracic medicine. Those doing work on intensive care units and on the subject of HIV and research into the basic sciences that have clear clinical links with our specialty should feel that Thorax is a potential home for such efforts. Many groups working in basic science disciplines do not have their own society journal and we hope that Thorax will attract innovative work that is not purely confined to clinical research and observation.

We also hope to continue to attract the best work from abroad-about half of submissions to Thorax currently are from outside Britain.

The date an article is received for consideration by Thorax will be added to the acceptance date on the front page of each published paper. This is to show our commitment to providing decisions rapidly to all who submit their research to us. Generally the delay from acceptance to publication has been as short as our technology allows.

We will encourage short reports that can succinctly describe new methods, new observations on established diseases, or trials with an important negative outcome, as well as the usual short clinical reports. Only $15-20 \%$ of the submitted case reports are accepted for publication. These reports must contain a teaching message that affects clinical practice or describe a usefully unique event if they are to stand a serious chance of acceptance for publication.

Conference reports and other updates are already planned and will appear from time to time.

I will be anxious for comments from the readers of Thorax - and please remember that there is a correspondence column that is as good as you make it.

Ultimately the success of a journal depends on the quality of papers submitted, the prompt, careful reviewing of manuscripts, and a close rapport with its readers.

The associate editors and I look forward to a stimulating time ahead.

Executive editor, Thorax 